\title{
Identification of Factors Associated with Breast Cancer Screening Based on the PEN-3 Model among Female School Teachers in Kermanshah
}

\begin{abstract}
Background and objective: Breast cancer is the most common cancer in women worldwide. Its incidence has increased in developing countries due to factors such as increase in life expectancy, urbanization and popularity of western culture. The aim of this study was to identify the social and cultural factors affecting breast cancer screening based on the PEN-3 model (perceptional, enabling and nurturers) among school teachers in Kermanshah, Iran.

Materials and methods: This study was a descriptive cross-sectional one. Through random sampling 258 high school teachers were selected as samples. A questionnaire that consisted with 50 questions based on the PEN-3 model was used to gather the data. The validity of the questionnaire was measured with content validity and the reliability with Cronbach alpha coefficient. The data were analyzed through SPSS 21 using one-sample t-test, two-sample t-test and Chi-square test.

Results: $48.1 \%$ of school teachers had a history of breast self-examination, $24.8 \%$ history of breast clinical examination by the physician and medical staff and $9.3 \%$ had at least one mammography. The most important affecting factors on screening were: belief to early detection of tumors (87.2\%), ability to pay the screening cost $(83.7 \%)$, negligence and forgetfulness (65.1\%), being busy and lack of time (56.2\%), fear (24.5\%), and anxiety (21.3\%).

Conclusion: Due to fact that the affecting factors on breast cancer screening behavior are in the scope of the social and cultural range, a comprehensive plan for intervention and using a health education model, including the PEN-3 model, can be useful.

Paper Type: Research Article.

Keywords: Early detection of cancer, Breast cancer; PEN-3 Model, Screening; School teachers, Kermanshah.

Citation: Naghibi S.A., Jamshidi P., Rostami F. Identification of Factors Associated with Breast Cancer Screening Based on the PEN-3 Model among Female School Teachers in Kermanshah. Iran J Health Educ Health Promot. Spring 2016;4(1): 58-64.
\end{abstract}

Seyed Abolhassan Naghibi

* Assistant Professor, Dept. of Public Health, Health Sciences Research Center, School of Health, Mazandaran University of Medical Sciences (MAZUMS), Sari, Iran (Corresponding author) Anaghibi1345@yahoo.com

Parvaneh Jamshidi

BSc Student in Public Health, Students Research Committee, School of Health, MAZUMS, Sari, Iran

Fereshteh Rostami

MSc in Epidemiology, School of Health, MAZUMS, Sari, Iran

Received: 07 May 2016 Accepted: 31 May 2016 


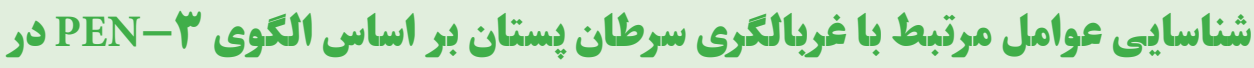 معلمان شهر كرمانشاه}

سيدابو الحسن نقيبى

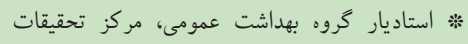

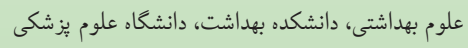

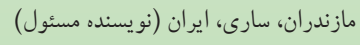
Anaghibi1345@yahoo.com

بروانه جمشيدى دانشجوى كارشناسى بهداشت عمومى، كميته تحقيقات

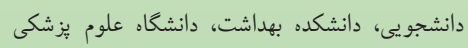

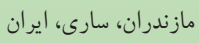
فر شته رستمى مازني

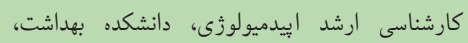

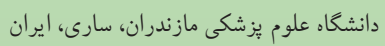

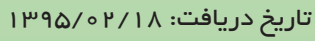

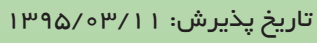

\section{بك}

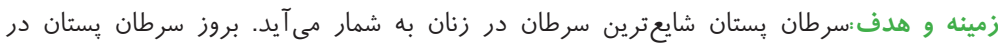

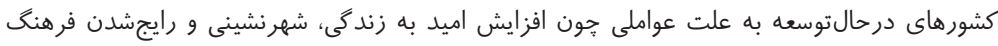

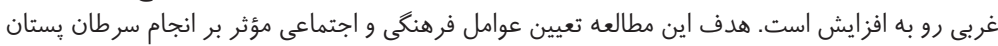

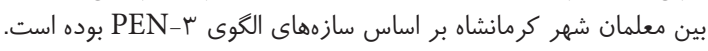

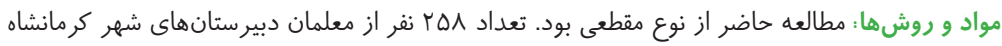

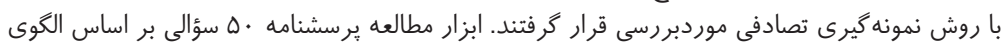

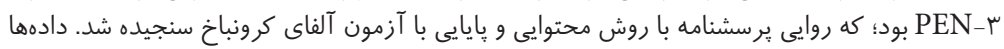

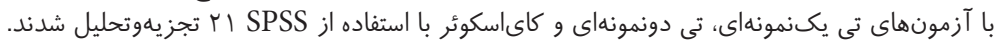

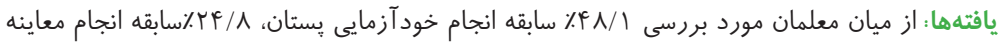

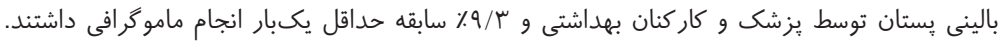

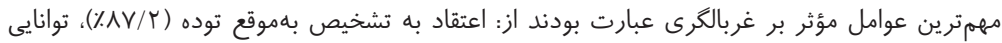

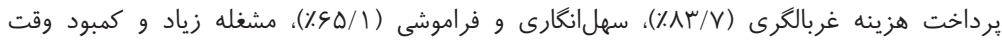

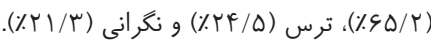

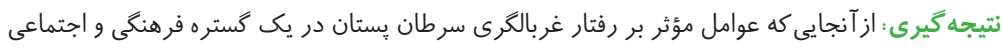

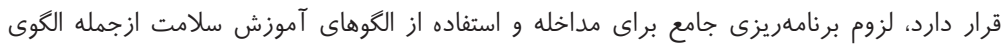

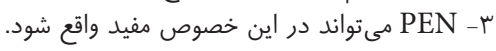

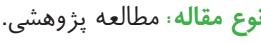

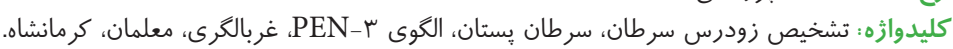

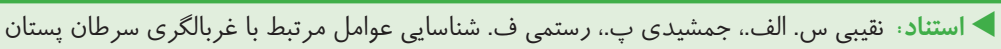

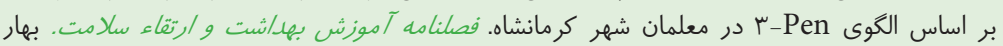

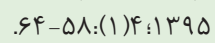


خصوص سرطان پِتان و اتخاذ رفتارهاى بهداشتى و نيز آموزش

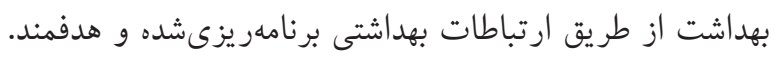

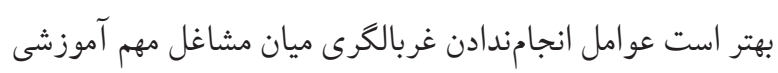

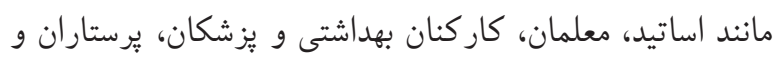

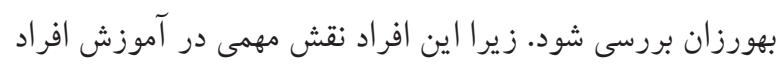

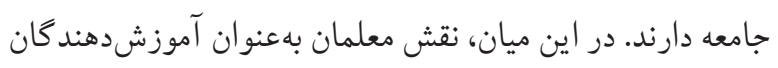

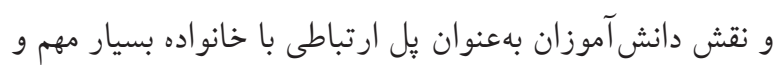
مشخص است.

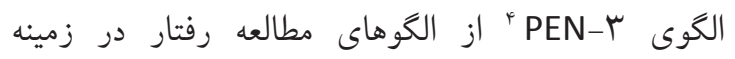

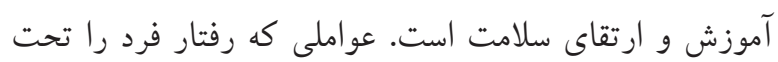

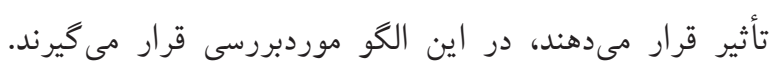

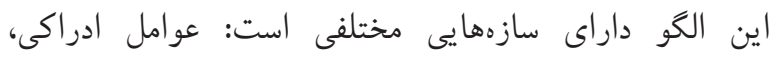
عوامل قادركننده و عوامل تقويت كننده؛ كه با خودباورهاى

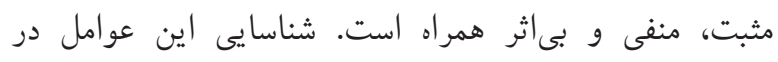

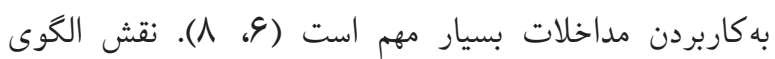

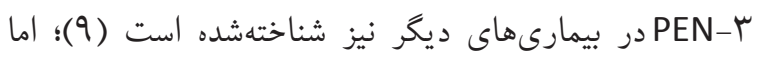

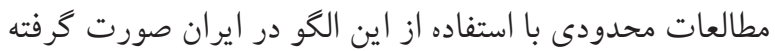

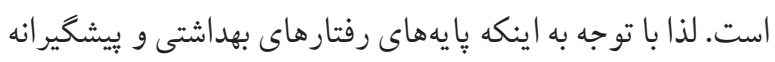

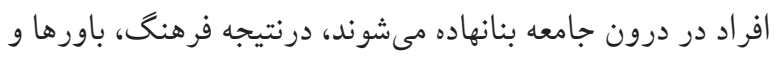

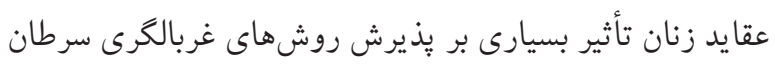

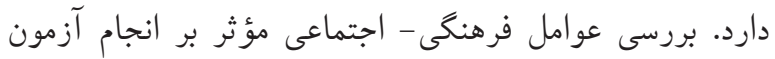

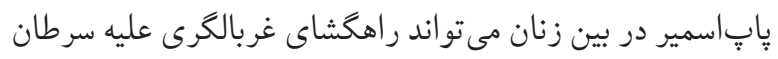

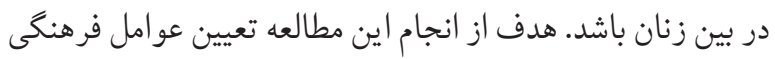

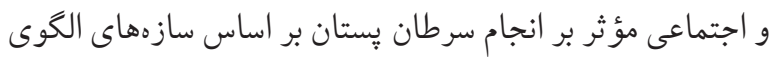

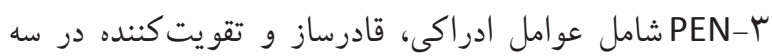
قسمت مثبت، منفى و بىاثر در معلمان شهر كرمانشاه بوده است.

\section{مو اد و روش ها} مطالعه حاضر از نوع توصيفى و مقطعى است. جامعه يُوهش،

4. PEN-1=Neighborhood Person Extend Family; PEN-2= Enablers Nurtures Perception; PEN-3=Negative Behaviors Existential Behaviors Positive Behaviors

سرطان بستان شايعترين سرطان در ميان زنان در كشورهاى درحالتوسعه و نيز در كشورهاى توسعهيافته است. بهطورى كه

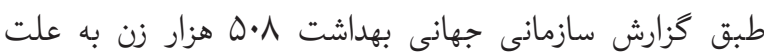

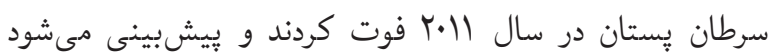

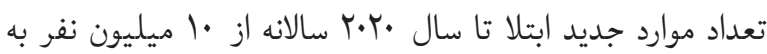
الميليون نفر برسد (1). بروز سرطان بستان در طول دهه اخير در اكثر كشورهاى درحال توسعه رشد سريعى داشته است. در ايران

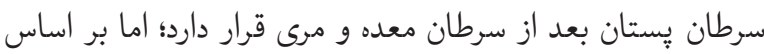

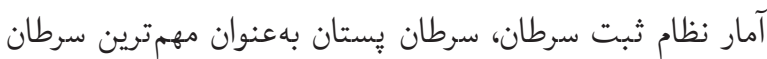

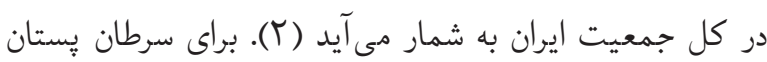
عوامل خطر متعددى برشمردهاند: بهبود شرايط اجتماعى اقتصادى،

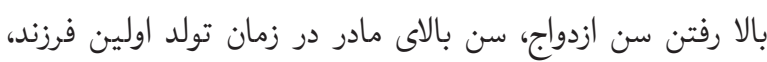

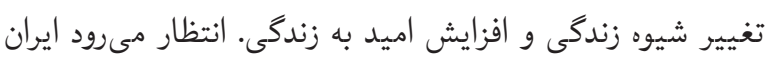

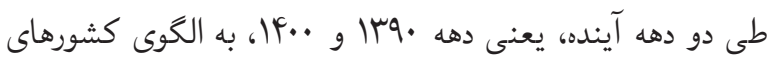
توسعه يافته نزديكتر شود (T- دام).

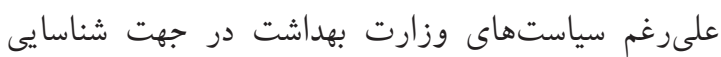
برخى عوامل مؤثر بر بروز سرطان پِّتان، به نظر مىرسد در

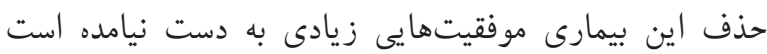
(9). تنها راه كاهش عوارض سرطان بِ بستان و بقاى عمر بيماران تشخيص زودرس سرطان با روشهاى غربالكرى است. تشخيص

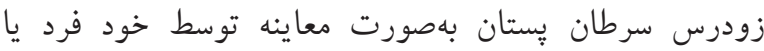

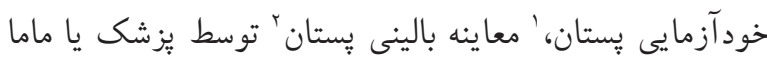

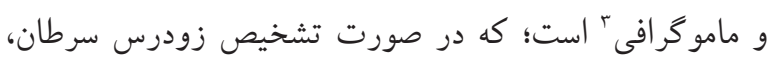
بيمارى قابل كنترل و درمان است (V) ونان بر اساس مطالعات صورت كَفتهه در داخل و در خارج كشور، راهكارهاى كنترل سرطان بستان در سطح اول نظام ارائه

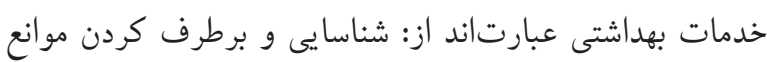

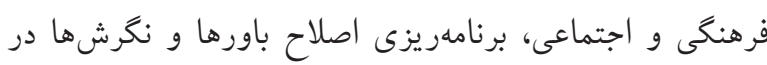

\footnotetext{
1. Breast Self Examination (BSE)

2. Clinical Breast Examination (CBE)

3. Mammography
} 
معيار ورود آزمودنىها به مطالعه معلمان شاغل در مدارس

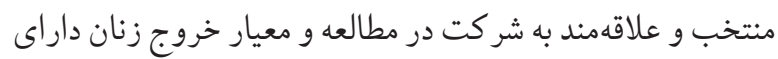
بيمارى سرطان پِتان بود. براى رعايت ملاحظات اخلاقى، قبل از تكميل يرسشنامه رضايت شفاهى نمونهها دريافت شد و به آنان

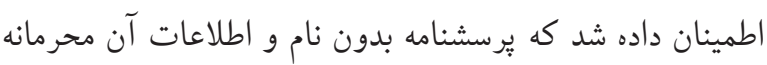

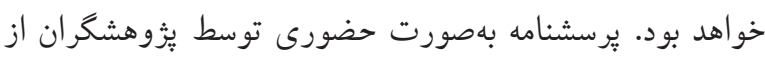

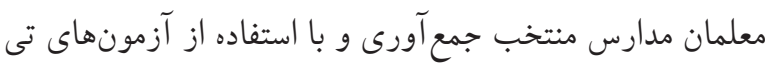
يكنمونهاى، تى دونمونهاى، كاى اسكوئر و آزمونهاى توصيفى در نرمافزار SPSS إ إ تجزيهو تحليل شدند.

يافتهاهـا

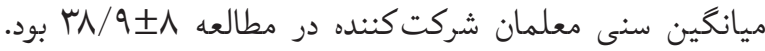

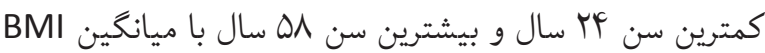

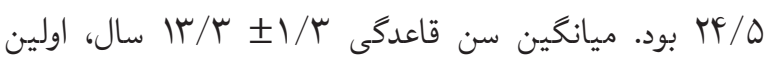

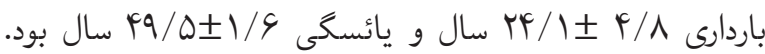
حدود IV ٪ از معلمان مجرد و NI/V ٪ متأهل بودند. سطح تحصيلات بيشتر افراد (VF/V) كارشناسى بوده است. وضعيت عوامل خطر بيمارى سرطان بِّتان در زنان موردمطالعه نشان

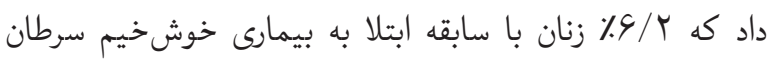

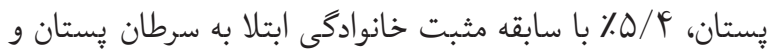

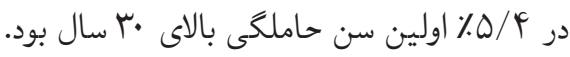
در مورد عملكرد استفاده از روشهاى تشخيص زودرس بس سلى

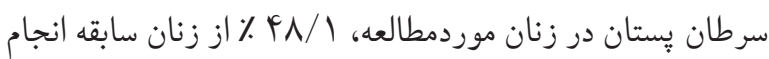

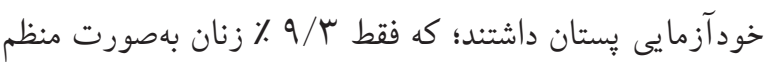

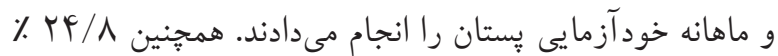

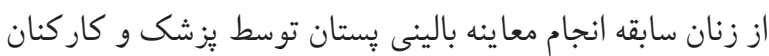

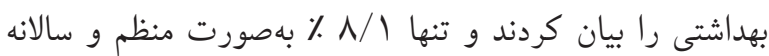

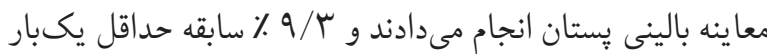

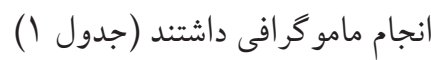

معلمان دبيرستانهاى سطح شهر كرمانشاه بود. با استفاده از روش

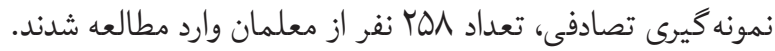
تعداد دبيرستانهاى دختر شهر كرمانشاه كاو دبيرستان بود؛ كه براى انتخاب نمونها به هر دبيرستان شهر كرمانشاه يك شماره اختصاص داده شد و با استفاده از جدول اعداد تصادفى تعداد 19 دبيرستان از نقاط مختلف شهر بهعنوان نمونه تعيين كرديد.

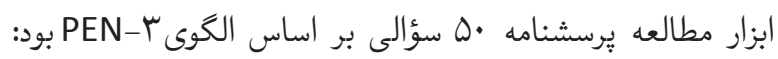

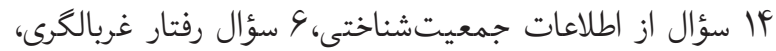
س سؤال عوامل ادراكى، سا سؤال عوامل قادرساز و سا سؤال

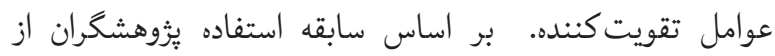

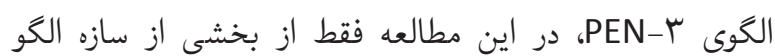

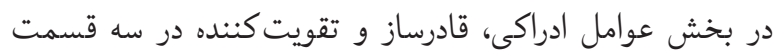
مثبت، منفى و بىاثر، براى نشان دادن تصويرى از باورهاى زنان در خصوص رفتار غربالخرى استفاده شد.

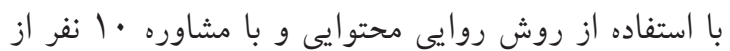
متخصصين و صاحبنظران بلصورت نظرى روايى يرسشنامه

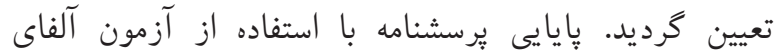

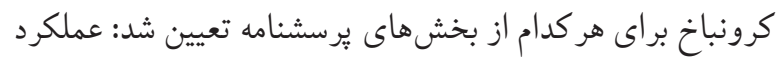

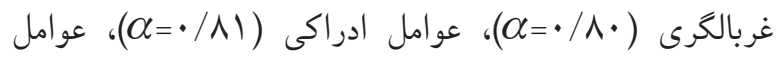

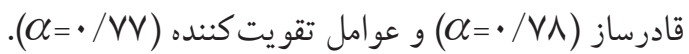
براى سنجش عملكرد روش غربالكرى سرطان پِّتان سؤ الات

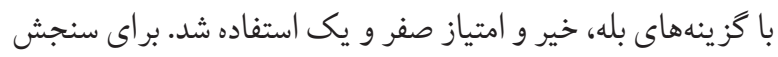

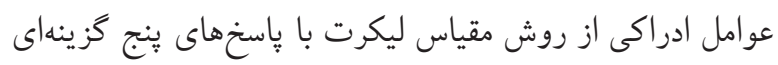

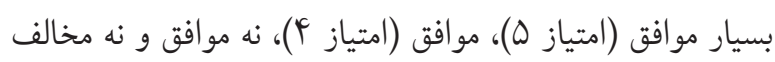

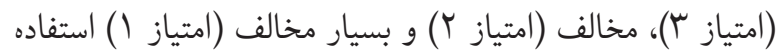

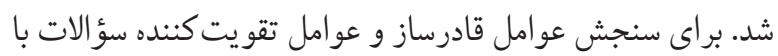
ياسخهاى بلى و خير و امتياز صفر و يك استفاده شد. در محاسبه

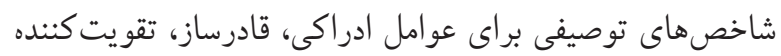

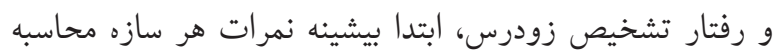

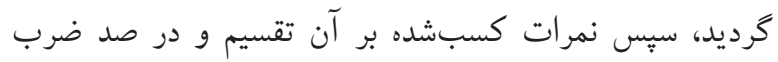
كرديد تا ميانگين با واحد يكسان براى سازهها محاسبه گردد. 


$$
\text { بود (1) ( p }
$$

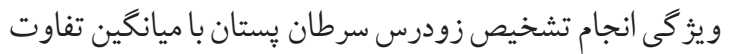

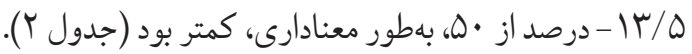

جدول r. محاسبه شاخص هاى توصيفى براى عوامل ادراكى،

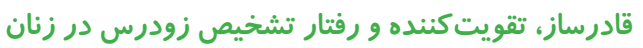

شر كت كننده در مطالعه

\begin{tabular}{|c|c|c|c|}
\hline معيار & ميانكين & تعداد & ويزگكى \\
\hline $9 / 4$ & $V V / 9$ & $10 \Lambda$ & عوامل ادراكى \\
\hline $1 r / 9$ & $r q / 1$ & 101 & عوامل قادرساز \\
\hline $1 N / 1$ & $\varphi \Delta / \Delta$ & 101 & عوامل تقويت كننده \\
\hline$\varphi \cdot / \mu$ & $r s / f$ & 101 & رفتار تشخيص زودرس \\
\hline
\end{tabular}

در ميان عوامل ادراكى در قسمت باورهاى مثبت، اعتقاد به

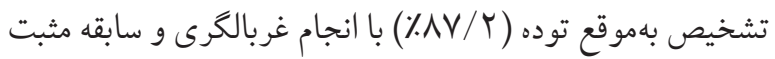
خو يشاوندى (IN) بيشترين موارد را به خود اختصاص داده بود.

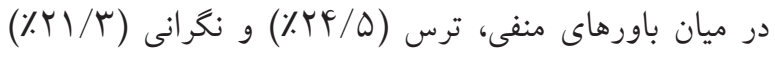

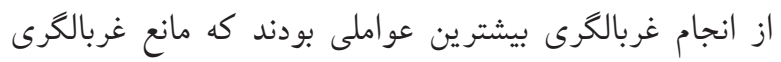

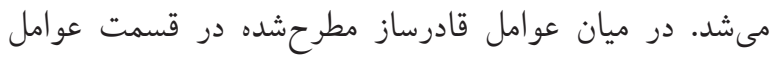

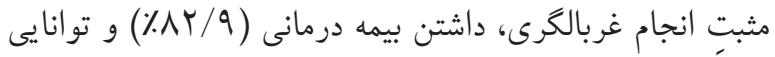

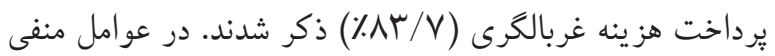

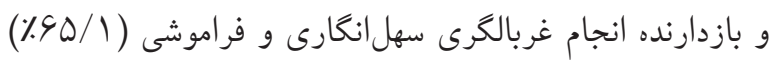
و داشتن مشغله و كمبود وقت (T/Y\&\%) بيان شدند. در ميان عوامل تقويت كننده نيز تشويق اعضاى خانواده و بهويزه همسر (\%VV/A)

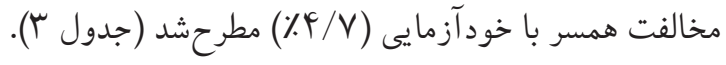

بحث در اين مطالعه به بررسى عوامل فرهنگى و اجتماعى مؤثر بر انجام

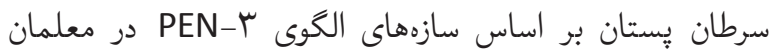
شهر كرمانشاه برداخته شد. نتايج مطالعات متعدد نشان داد كه الخوى ب-PEN در شناسايى راههاى بيشخيرى كمك كننده است

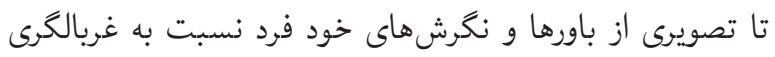
سرطان پِتان ارائه دهد؛ اما مطالعات محدودى در اين زمينه
جدول ا. فراوانى نسبى رفتار تشخيص زودرس سرطان يُتان زنان شركت كننده در مطالعه رودي

\begin{tabular}{|c|c|}
\hline درصد & سؤات \\
\hline \multicolumn{2}{|r|}{ سابقه انجام خود آزمايى يستان } \\
\hline 「人/1 & بلى بلى \\
\hline $01 / 9$ & خير \\
\hline \multicolumn{2}{|r|}{ سابقه انجام معاينه بالينى پستان } \\
\hline$r F / \Lambda$ & 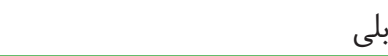 \\
\hline$V \Delta / r$ & خير \\
\hline \multicolumn{2}{|r|}{ سابقه انجام ماموگر افى } \\
\hline $9 / \mu$ & 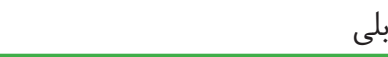 \\
\hline $9 \cdot / V$ & خير \\
\hline
\end{tabular}

در خصوص ارتباط ويثگىهاى جمعيتشناختى با انجام

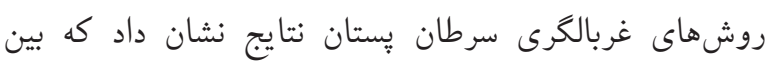

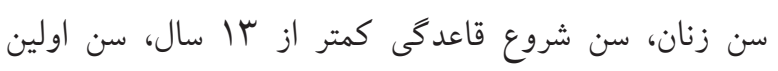

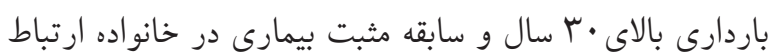

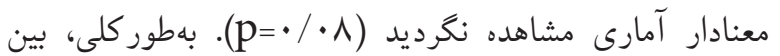

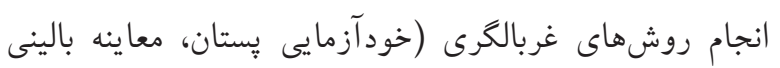

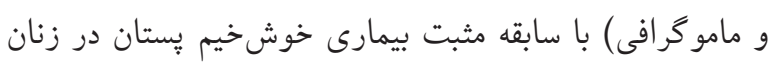

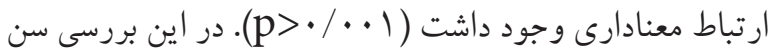

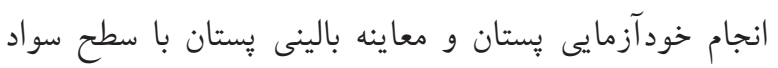

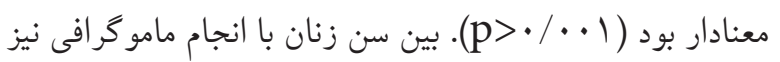

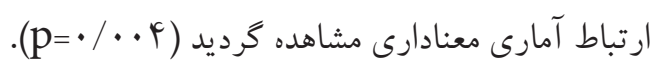
با مقايسه امتيازات عوامل ادراكى، قادرساز، تقويت كننده

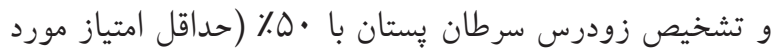

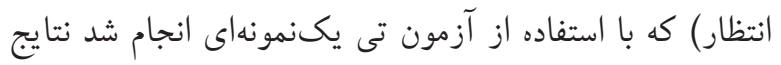
زير بهدست آمد:

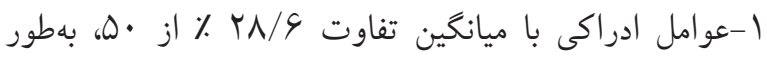

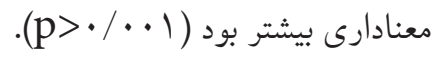

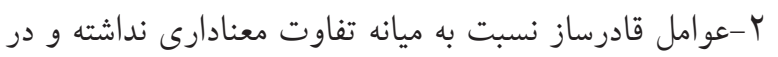
حدود معا ينه بالينى بود.

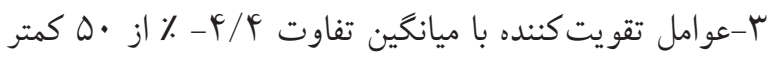


جدول س. سازههاى الخوى ب-PEN (عوامل ادراكى، قادركنندهو تقويت كننده) در موردانجام سرطان سينه در زنان شركت كننده در مطالعه

\begin{tabular}{|c|c|c|c|}
\hline بىاثر & منفى & مثبت & عوامل \\
\hline 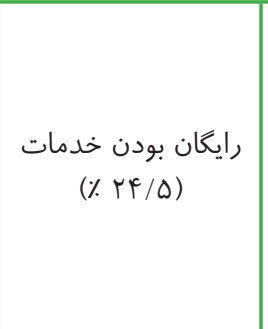 & 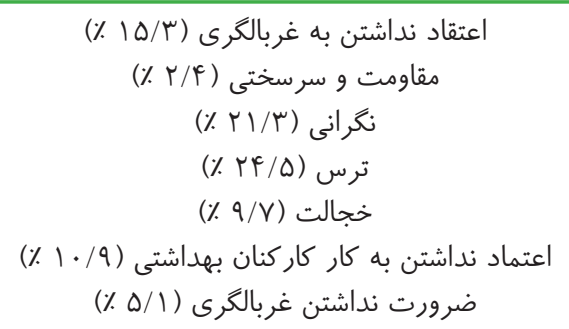 & 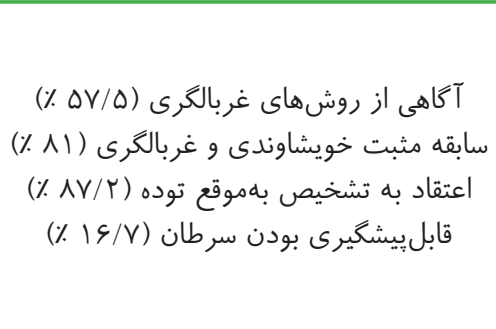 & ادراكى \\
\hline زمانبر و صرف وقت (هV/F & 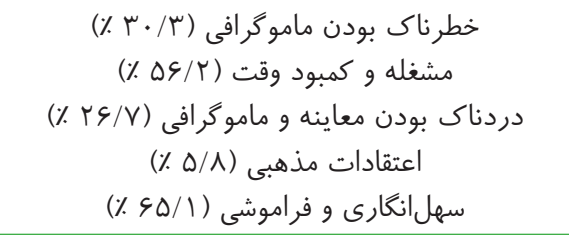 & 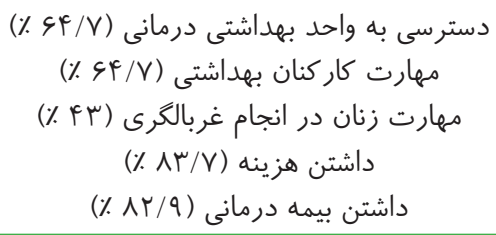 & قادرساز \\
\hline تكرارى بودن (Ar/A ٪) & 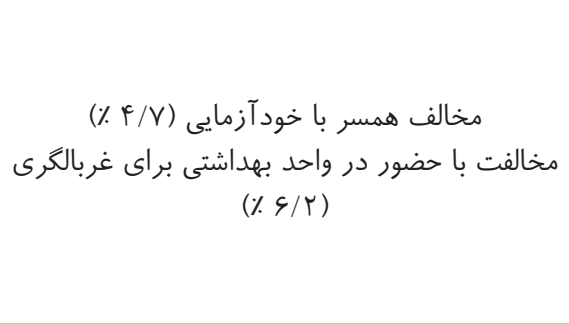 & 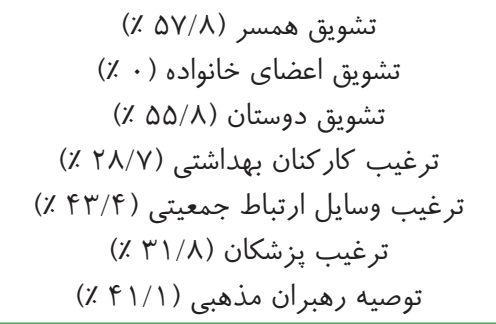 & تقويت كننده \\
\hline
\end{tabular}

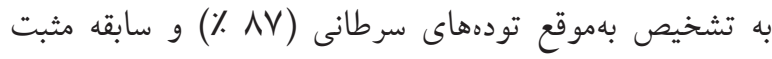

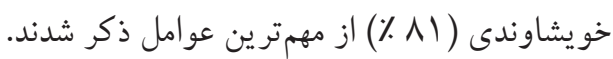

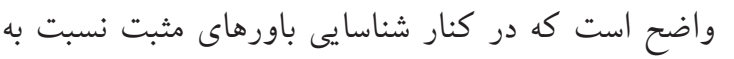

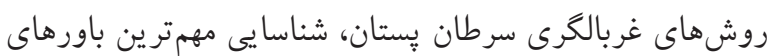

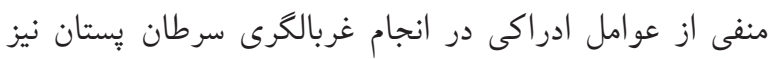

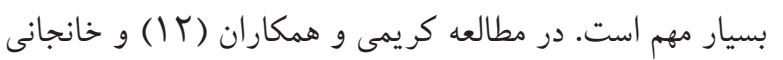

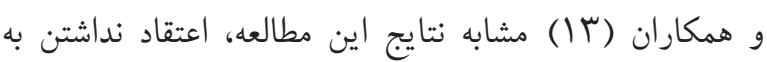
غربالكرى، ترس و نكرانى از انجام غربالكرى از دلايل مهم انجام

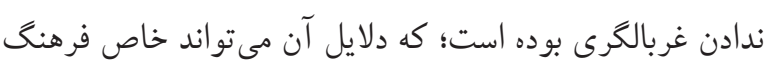

$$
\text { و عقايد مردم باشد. }
$$

نتايج مطالعه حاضر نشان داد كه سهلانگارى و فراموشى باند از مهمترين موانع قادرساز در غربالكرى سرطان پِّتان است. در مطالعه خداياريان و مظلومى (1) (1) نيز همانند اين مطالعه

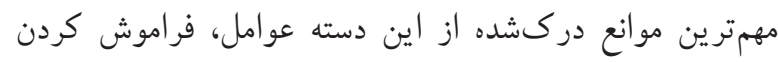

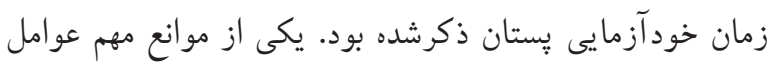

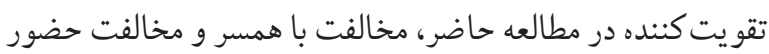

صورت گرفته است.

ميانگين نمره عو امل ادراكى در سطح مناسب و بالاتر از ميانه

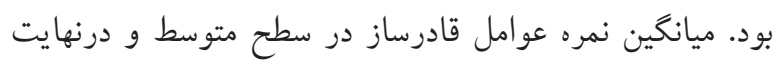

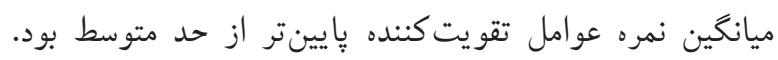
انجام رفتار تشخيص زودرس خيلى گيايينتر از حد متوسط بود.

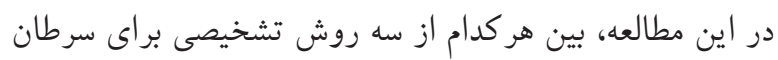

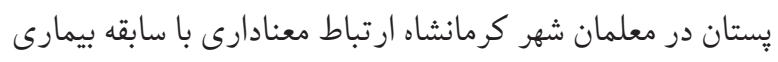
خوشخيم بستان وجود داشت.

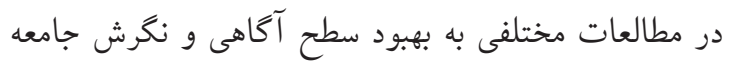
نسبت به سرطان و نقش مثبت آن بر رفتارهاى غربالكرى افراد جامعه تأكيد شده است؛ بهطورى كه در مطالعه كدازنده و همكاران

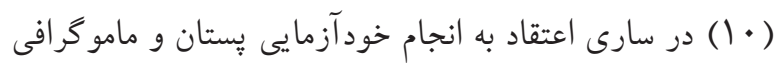
به ترتيب AV و 9V ٪ بود، درحالى كه در مطالعه خداياريان و مظلومى (1) (1) مهمترين موانع دركشده خودآزمايى بستان،

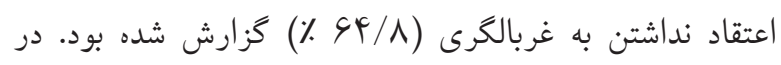
مطالعه حاضر، همانند مطالعه كدازنده و همكاران ( • () ، اعتقاد 
براى مداخله و استفاده از الكوهاى آموزش سلامت ازجمله الكوى PEN- مى تواند در اين خصوص مفيد واقع شود. با توجه به اينكه در اين مطالعه قسمتى از الخوى بكار گرفتهشده است، لذا

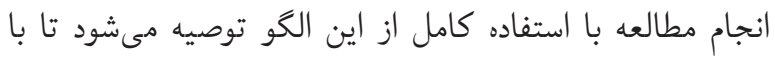
شناخت عوامل فرهنگىى، اجتماعى و اقتصادى تأثيرگذار بر انجام غربالكرى سرطان يستان، با توجه به سياستهاى وزارت بهداشت،

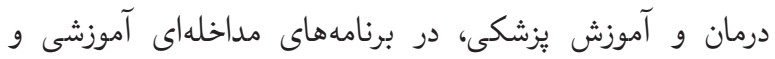

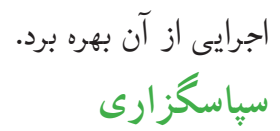

اين مقاله از طرح مصوب دانشجويى با كد MTD استخراجشده است. بدينوسيله از معلمان شركت كننده در مطالعه و از معاونت

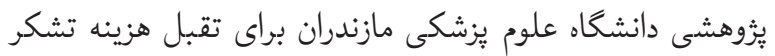

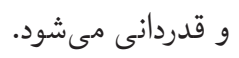

\section{References}

1.http://www.who.int/nmh/publications/ncd_report_ chapter1- Burden: mortality, morbidity and risk factors. (Updated November 2013).

2. Ministry of health and medical education cancer for disease control and prevention Non- communicable disease unit in Iran. January 2012.

3. Weinbreg RA, Komaroff AL. Your lifestyle, your genes, and cancer. News Week 2008; 151(26): 40-3.

4. Weihofen D. Fighting cancer with food and nutrition. Society of Gynecologic Nurse Oncologists 2010; 20(1): 22-35.

5. Mendelsohn JB, Li QZ, Ji BT, Shu XO, Yang G, Li HL, et al. Personal use of hair dye and cancer risk in a prospective cohort of Chinese women. Cancer Sci 2009; 100(6): 108891.

6. Didarlo A, Shojaeezade D, Mohamadian H.A Textbook of Health promotion planning. 1nd ed. Sobhan,Tehran:2007. [Persian]

7. Naghibi A, Shojaizadeh D, Montazeri A and YazdaniJ. Sociocultural Factors Associated with Breast SelfExamination among Iranian Women.ActaMedicalranica, 2015; 53(1):62-68[In Persian].

8. Sheppard VB, Figueiredo M, Cañar J, Goodman M, Caicedo L, Kaufman A, Norling G, Mandelblatt J. 'Latina a Latina: developing a breast cancer decision support intervention' in Psychooncology. 2008 Apr; 17(4):383-91.

9. Joan E, Shandowyn P, Amy Th. Application of the PEN-3 Model in a Diabetes Prevention Intervention. Journal of
در واحدهاى بهداشتى براى غربالحرى بود؛ با مطالعه خداياريان و مظلومى (11) نيز همراستا بود. گر جه در مطالعه حاضر انتظار مىرفت عو امل قادرساز و تقويت كننده همانند عوامل ادراكى در افراد بهطور معنادارى افزايش يابد، اما اين نتيجه بهدست نيامد. به نظر مىرسد علت آن تفاوت در عوامل فرهنكى و اجتماعى افراد هر منطقه باشد. لذا بايد با انجام مطالعه در افراد متفاوت و در اقشار متفاوت مشكلات مربوطه شناسايى و در راستاى آن با توجه به سياستهاى موردنظر اقدام گردد. اين در حالى است كه تأثير آموزش و آكاهسازى زنان جامعه در ترغيب آنها به انجام غربالكرى در مطالعات متعددى به اثبات رسيده است (F ا -ه ا ). نتيجه كيرى ازآنجايى كه عوامل مؤثر بر رفتار غربالكرى بر سرطان يستان در يك گستره فرهنگى و اجتماءى قرار دارد، لزوم برنامهريزى جامع Health Disparities Research and Practice.2010; 4(1): 26 41.

10. Godazande GA, Khani H, Khalilian AR, Attard Z, Firozjaee MA, Partovi A. Knowledge and practice of above 15 years old female toward breast cancer prevention in Sari township. J of Mazandaran University of Medical sciences 2004; 16(52): 64-74. [Persian]

11. Khodayarian M, Mazloomy M. Assessment of awareness and attitude of women about breast cancer screening behavior in Yazd city, Iran in1391.Iranian Quarterly Journal of Breast Disease 2013; 6(2). [Persian]

12. Karimy M, Hasani M, Khorram R, Gafari M, Niknami SH. The Effect of Education Based on Health Belief Modelon Breast Self- Examination in Health Liaisons of Zarandieh City. Zahedan Journal of Research in Medical Sciences.2009; 10 (4): 283-91. [Persian]

13. Khanjani N, Noori A, Rostami F. The Knowledge and Practice of Breast Cancer Screening among Women inKerman, Iran. AlAmeenJ Med Sci. 2012; 5 (2): 177-82.

14. Stetz KM, Haberman MR, Holcombe J, Jones LS: 19940ncology Nursing Society Research Priorities Survey. OncolNursForum 1995, 22:785-789. Abstract.

15. Kalan Farman KH, Jalili Z, Zareban I, Shahraki Pour M. Effect of education on preventive behaviors of breast cancer in female teachers of guidance schools of Zahedan city based on health belief model. Journal of Education and Health Promotion2014;3. [Persian] 